\section{EMBRYARIDDLE}

Aeronautical University

SCHOLARLY COMMONS
Journal of Aviation/Aerospace

Education \& Research

Volume 26

Number 2 JAAER 2017

Article 4

2017

\title{
Forecasting the Air Race Classic: Lessons in Interdisciplinary Aviation Weather Support and Decision-Making
}

Shawn M. Milrad

Embry-Riddle Aeronautical University - Daytona Beach, milrads@erau.edu

Debbie Schaum

Embry-Riddle Aeronautical University - Daytona Beach, schaumd@erau.edu

Follow this and additional works at: https://commons.erau.edu/jaaer

Part of the Educational Methods Commons, Management and Operations Commons, Meteorology Commons, and the Science and Mathematics Education Commons

\section{Scholarly Commons Citation}

Milrad, S. M., \& Schaum, D. (2017). Forecasting the Air Race Classic: Lessons in Interdisciplinary Aviation Weather Support and Decision-Making. Journal of Aviation/Aerospace Education \& Research, 26(2). https://doi.org/10.15394/jaaer.2017.1715

This Article is brought to you for free and open access by the Journals at Scholarly Commons. It has been accepted for inclusion in Journal of Aviation/Aerospace Education \& Research by an authorized administrator of Scholarly Commons. For more information, please contact commons@erau.edu. 


\section{Introduction and Motivation}

\section{Research Question and Objectives}

Eyler (2002) defined academic service-learning as university coursework combined with community service. As Eyler (2002), Eyler and Giles (1999), and Boyer (1994) also pointed out, service-learning helps students to feel more purposeful and connected to both each other and the outside world. This generally leads to a more engaged learning environment and the acquisition of "real-world" skills. More recently, both Furco, Jones-White, Huesman, Jr., and Gorny (2016) and Kricsfalusy, George, and Reed (2016) have quantitatively demonstrated the beneficial aspects of service and project-based learning across multiple disciplines and institutions. In this article, the development and execution of a novel interdisciplinary service and experiential learning course at Embry-Riddle Aeronautical University Daytona Beach (ERAU-DB) in support of the Air Race Classic (ARC) are discussed. The course combines aviation and meteorological concepts and educational techniques, while giving students a sense of purpose in providing necessary and useful information to real-time end users. The goal of this experimental course is to assess and improve the abilities of students with various levels of aviation and meteorological backgrounds to present unified weather support for a real-time customer. The success of this educational initiative is judged by the responses and level of engagement of the students, the trust built with and satisfaction of the customer, and the degree to which the course advances service and experiential learning in aviation and meteorology.

This article first presents an overview of the ARC and details the structure of the experiential learning weather support course, including pre-race lecture objectives and new ways of thinking that a student of a particular educational background must be introduced and adapt to during the course. Subsequently, relevant weather support scenarios from both the 2015 and 
2016 ARC races are presented. Finally, lessons learned and student retrospectives from the ARC course are discussed.

\section{Air Race Classic (ARC) History and Overview}

The ARC is an all-female Visual Flight Rules (VFR) air race held each June (Air Race Classic [ARC], 2016a). The race started in 1929 as the Powder Puff Derby; prior to 1929, air racing by women was not allowed (ARC, 2016a). Air racing subsequently went into a holding pattern during World War II. In 1949, the Women Air Service Pilots (WASPs) who had been dismissed from the Army after the war wanted to continue to log flight hours (ARC, 2016a). Through the Ninety-Nines organization, women's air racing had a rebirth called the All Woman Transcontinental Air Race (AWTAR). The current ARC was started in 1977 by former AWTAR racers (ARC, 2016a).

The goal of the ARC is to "conduct an annual extended cross country air race for women and to perform any and all acts which may be helpful, necessary or desirable in promoting, organizing, and staging said race" (ARC, 2016a). The race length is approximately 2,500 statute miles. Aircraft are single engine, and are handicapped based on make and model, with adjustments for modifications.

The teams consist of at least two women pilots, each with private or higher airman's certificate and a rating for the class airplane they are flying. There is a sub category called the Collegiate Division. To qualify, racers must be closely affiliated with a university and the team pilot must be a registered undergraduate student of the university they are representing. The university teams compete within the Collegiate Division as well as against the rest of the racers.

During the race, the racers must maintain VFR rules. They must fly a timing line at the terminus for each leg to start their time for a leg or stop their time for the leg just flown. Flying 
is only allowed between sunrise and sunset. Pilots may only land for fuel or remain overnight at one of the designated race stops. There are numerous ways to obtain penalties, from not following proper procedures flying the timing lines to fueling ahead of someone in line without permission. Winners are determined by how well they did in comparison to their own handicap and penalties. In order to be successful, the team must use the wind and weather to their advantage.

ERAU-DB's first involvement in the ARC began in 1996 but the university did not participate from 1997-2006, inclusive. ERAU-DB began entering the race again in 2007, and in 2008, the ERAU-DB race team was sponsored for the first time. In 2013, the Meteorology Program first provided coordinated weather support, using aeronautical science students studying to acquire their Federal Aviation Administration (FAA) dispatch certification on a volunteer basis. This led to the creation of a formal three-credit summer course in 2014 (see Table 1). ERAU-DB's performance in the ARC has been particularly strong since organized weather support started in 2013 with several $1^{\text {st }}$ place finishes in the collegiate division (see Table 1). This culminated in a $1^{\text {st }}$ place overall finish in 2016 during the third year of the formal summer course. Consistent improvement, and in recent years, overall excellence in race performance, can be traced to the development of a coherent and collaborative weather support team through the service learning course.

Figure 1 shows the ARC race courses for 2015 and 2016 (ARC, 2016b). The 2015 ARC course was located primarily east of the Mississippi River (see Figure 1), with the primary challenges being: (a) the high terrain and possible Instrument Flight Rules (IFR) conditions in/near the Appalachian Mountains, and (b) the general east-to-west course, which meant aircraft flying against the climatological west-to-east jet stream. Unlike more common west-to-east 
courses (e.g., the 2014 and 2016 ARC races), one of the primary 2015 challenges was mitigating the impact of headwinds, especially during the first few legs.

Table 1

Selected History of ERAU-DB ARC Participation and Results, and Notable Benchmarks in Weather Support by the ERAU-DB Meteorology Program

Year ERAU-DB Significance $\quad$ ERAU-DB Performance

1995 First participation in race

2007 Resumed participation in race

2008 First sponsored race team

$28^{\text {th }}$ overall (collegiate data unavailable)

2009

$1^{\text {st }}$ collegiate, $8^{\text {th }}$ overall

2011

$8^{\text {th }}$ collegiate, $25^{\text {th }}$ overall

2012

$1^{\text {st }}$ collegiate, $2^{\text {nd }}$ overall

2013 First use of volunteer students studying to receive $\quad 1^{\text {st }}$ collegiate, $3^{\text {rd }}$ overall their FAA dispatch certification

2014 First offering of undergraduate course

$1^{\text {st }}$ collegiate, $2^{\text {nd }}$ overall

2015 Second offering of undergraduate course;

$4^{\text {th }}$ collegiate, $6^{\text {th }}$ overall

supported two race teams for the first time

2016 Third offering of undergraduate course; supported four total race teams (two student teams, one faculty team, and one contributor team)

$1^{\text {st }}$ collegiate, $1^{\text {st }}$ (student team) and $3^{\text {rd }}$ (faculty team) overall

In 2016, the ARC had a unique relationship with ERAU in that it began at the ERAUPrescott, Arizona campus and terminated at ERAU-DB. Some weather-related challenges included the: (a) complex and high terrain in the southern Rockies, particularly near Albuquerque, New Mexico (KAEG, see Figure 1); (b) extremely high (> $3000 \mathrm{ft}$ ) density altitude corrections in abnormally hot weather from Arizona to Texas; (c) Great Plains low-level jet 
(LLJ), a current of south-to-north strong winds climatologically favored from evening to midmorning; and (d) regular threat of thunderstorms in the central and eastern U.S. (including Florida) during early summer.

The number of aircraft supported by the ERAU-DB weather support team has also increased over time. In 2015, ERAU-DB had two student race teams for the first time. In 2016, there were two student teams, one faculty team, and one university contributor team (four total teams received weather support). Ensuring that the students in the course understood the needs and limitations of each flight team and that each flight team understood the objectives of the weather support team was crucial to the success of the program and the racers.
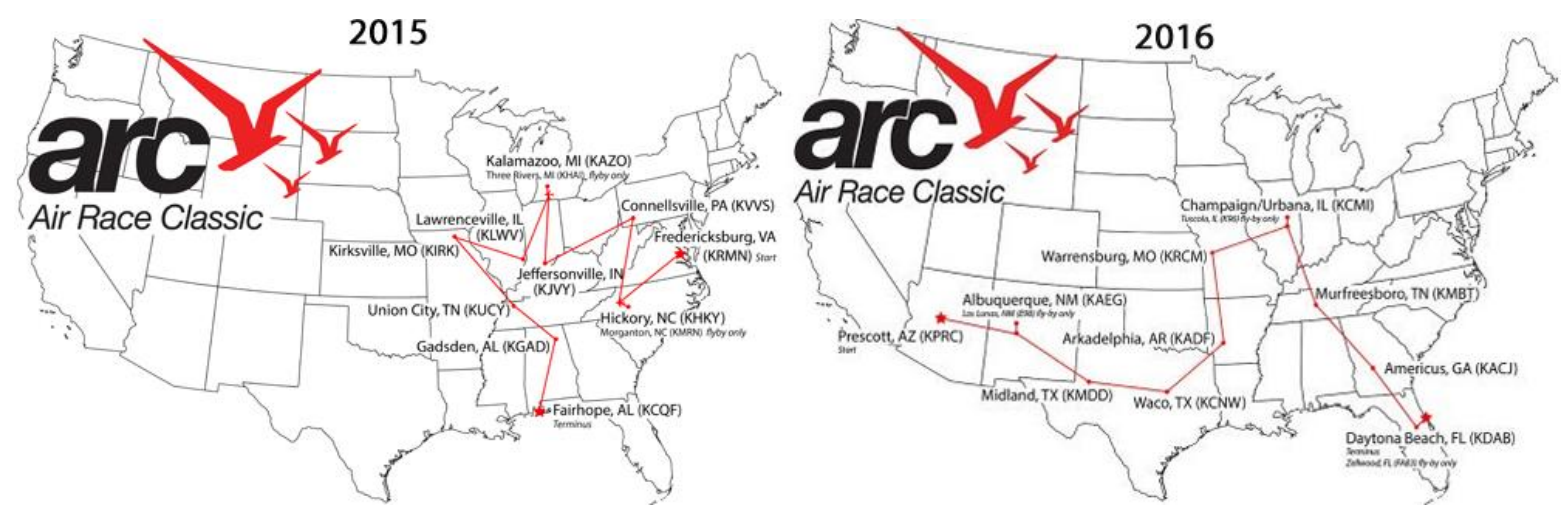

Figure 1. The ARC race courses for 2015 and 2016 (ARC, 2016b).

\section{Class Objectives and Interdisciplinary Service Learning}

In the ARC course, students come in with diverse educational backgrounds, ranging from meteorology majors to aeronautical science majors. Aeronautical science majors are primarily students training to be professional pilots at various certificate levels. A third group of students, aiming to acquire their FAA dispatch certification and be professional dispatchers, usually come into the course with a combination of meteorology and aviation experience. Students realize 
early in the course that their actions will contribute to the overall success of the ERAU-DB ARC race team(s), and their level of engagement in class activities typically increases immediately. Eyler (2002) described true service-learning as that which not only engages student interest, but creates positive attitudes towards "community engagement" and a sense of "personal efficacy and commitment". Students also quickly develop "lifelong learning and problemsolving skills" (Eyler, 2002). ARC students have certainly exhibited these traits in the three years (2014-2016) during which it has been offered for credit. During the 2016 ARC, most of the students in the course showed extreme dedication to the event, often working 6-10 hour shifts each day during race week with no financial incentive. What makes this experiential learning environment unique is the diverse educational background of the students, the service opportunity that the ARC race provides, and the interdisciplinary approach to weather support that is encouraged. The primary goals of the ARC three-credit course are to:

- Provide constant and consistent weather support to the ERAU-DB race team(s) in preparation for and during the ARC.

- Educate students from aviation backgrounds how to "think like an aviation meteorologist" and utilize weather support tools they may not be a priori familiar with.

- Educate students from meteorology backgrounds how to "think like an aviator" and utilize flight and dispatch tools they may not be a priori familiar with.

- Integrate the diverse educational backgrounds of the students so that they work as a cohesive weather support team; that is, have each student utilize their inherent strengths and successfully integrate new concepts and types of thinking. 


\section{Pre-Race Learning Objectives, Tools, and Techniques}

The first idea that students must understand is the crew resource management concept of air racing. The pre-race lecture portion of the course begins with the pilot requirements and ARC rules so that students can understand the customer's (i.e., the race teams') needs. Each year, the race teams visit for a lecture period early in the course to meet the weather support students and detail their racing style and preferences. This helps to ensure that during the race, there is an established trusted relationship between the racers and the weather support team. In addition, students need to study and understand the capabilities and limitations of each aircraft for which they will be providing weather support. This allows the students to tailor weather support specifically to the needs of each crew. Figure 2 shows a chart and photo of an ERAUDB race aircraft during the 2014 ARC; this was introduced to the students at the very beginning of the pre-race lectures, so that they were immediately aware of concepts such as service ceiling and fuel consumption.

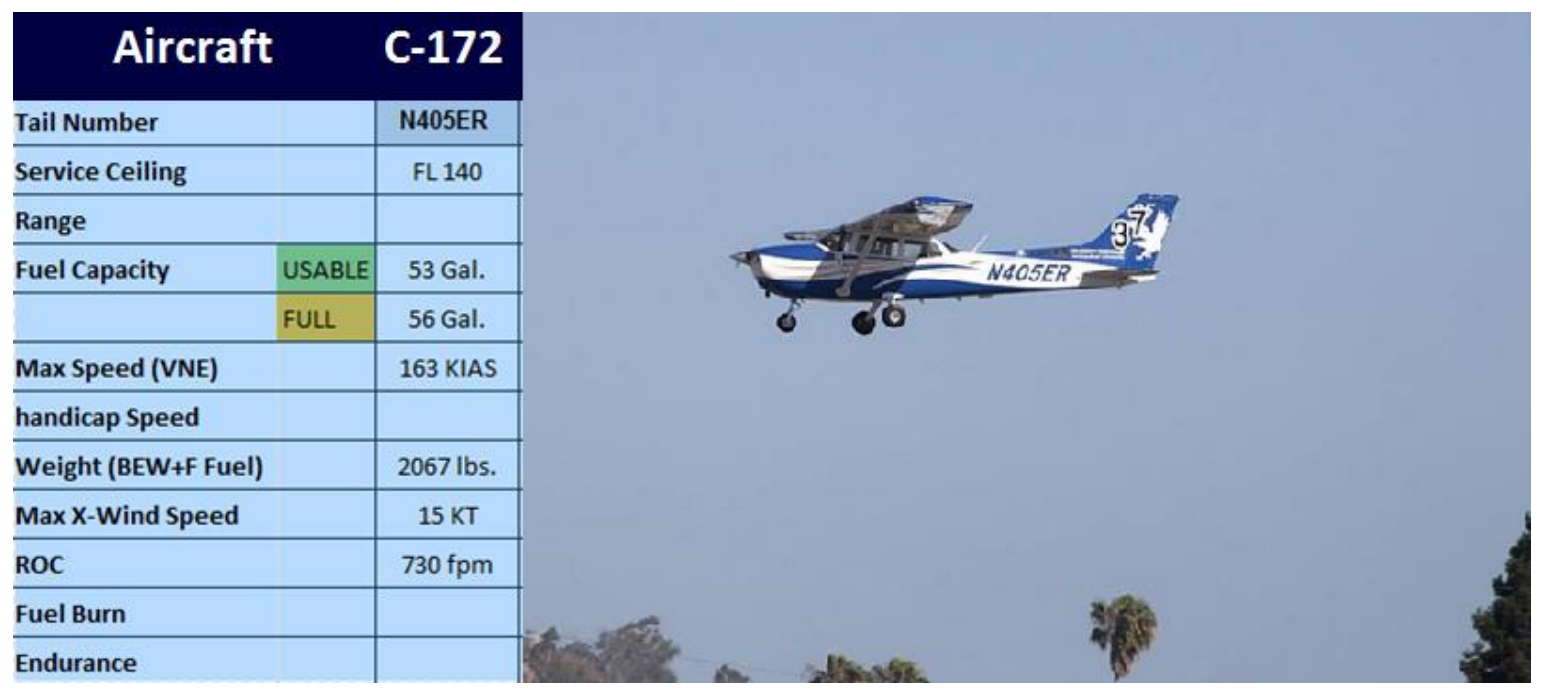

Figure 2. ERAU-DB (C-172) aircraft capabilities and photo in preparation for the 2014 ARC. 
After studying each terminus and flyby location (see Figure 1), students studied the flight path of each ARC leg. Students also researched the location of all obstacles along the flight path, including towers, restricted area flight levels, and times of operations. Learning the basics of dispatching for an air race also means the students needed to develop a better understanding of how weather and aircraft performance are related. For example, many students have never flown in mountainous terrain, particularly under extreme density altitude conditions. Studying the portions of the race course where high terrain is a factor allowed them to understand the limitations of each aircraft's ability to handle mountain flying and safety concerns. Based on the abilities of the aircraft and including such factors as density altitude, service ceiling, and terrain height, students looked for possible alternate routes.

Figure 3 shows a FAA VFR chart (Federal Aviation Administration [FAA], 2016a) used for the 2016 ARC course, another tool that we introduced in early pre-race lectures. The chart includes all terrain hazards and Military Operation Areas (MOAs) for the length of the race course. Students are expected to become familiar with all possible obstacles to VFR flight well in advance of the ARC.

During ARC pre-race lectures, weather forecast tools designed to maximize the use of tailwinds and avoid IFR conditions are introduced. Examples of a few such tools for both the 2015 and 2016 ARC are presented in the next section, from both aviation/dispatch and meteorological/forecast perspectives. Later, students began to develop tools for supporting the racers and create standardized methods of communication. For example, the weather support students divided into groups and practiced creating race day information worksheets (fuel burn, distance, possible along-route weather hazards) to be disseminated to each race team before an ARC race day. This entire process provided students with the knowledge necessary for 
understanding and forecasting for a real-world customer; that is, maximizing the use of weather and winds for the purpose of racing.

The ARC course is comprised of students of very diverse educational backgrounds. This creates the need to tailor the course to multiple perspectives, with an ultimate goal of integrating those perspectives into a cohesive weather support team by the start of the ARC.

\section{Integrating Meteorology into Aviation}

Before being able to provide weather support, aeronautical science and dispatch students must study and become familiar with regional terrain, climatology, available weather information for each terminus and fly-by location, and various aviation weather forecasting tools and techniques. For example, they must be able to answer basic climatology questions such as:

- What are the prevailing climatological winds during the week of the ARC?

- Are extreme density altitude corrections (due to heat and elevation) possible in certain locations during the ARC, and if so, how will it impact the aircrafts' service ceilings?

- Are particular ARC course locations prone to thunderstorms and if so, at what time of day?

- Are there bodies of water at a particular location in the race course that could cause morning fog, potentially delaying a sunrise takeoff? 


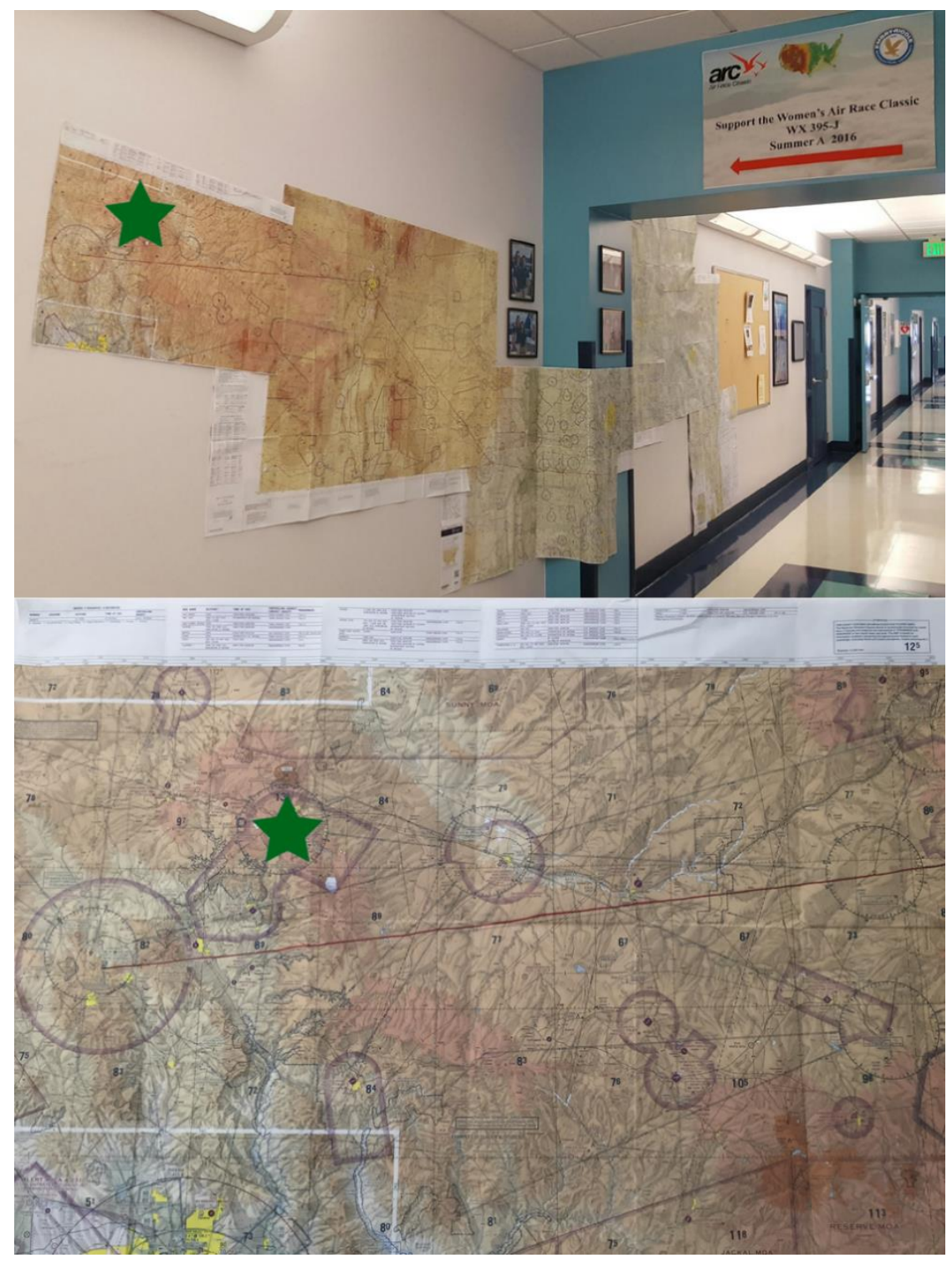

Figure 3. Federal Aviation Administration (FAA) Visual Flight Rules (VFR) charts of the 2016 ARC race course (top) and first race leg (see Figure 1) from Prescott, Arizona to Albuquerque, New Mexico (bottom), as displayed in the ERAU-DB Meteorology Program hallway during June 2016. The 2016 ARC starting point (ERAU-Prescott) is marked with a green star on each panel. 


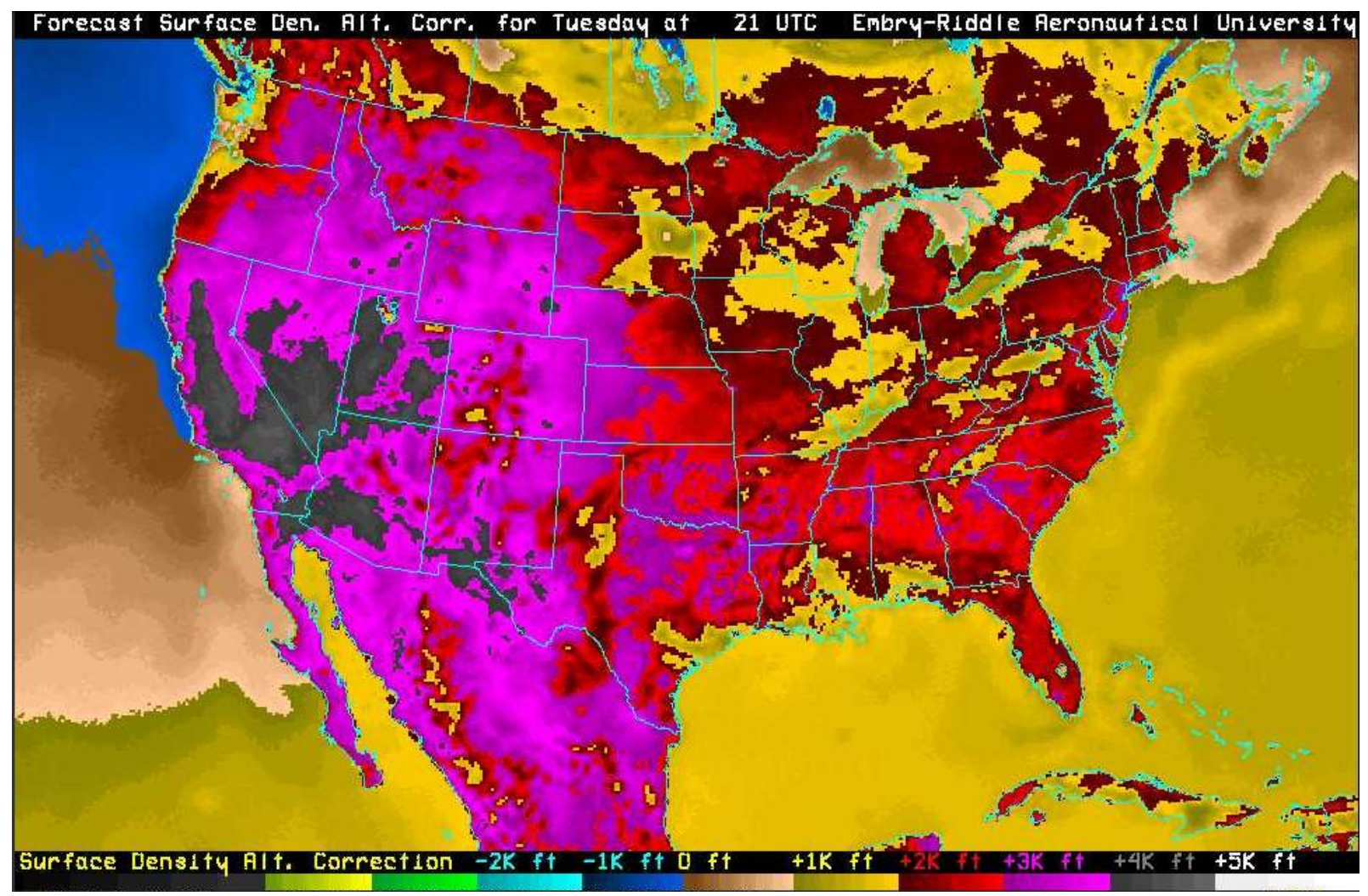

Figure 4. ERAU-DB Flight Weather surface density altitude correction model forecast valid at 2100 UTC 26 July 2016 (Embry-Riddle Aeronautical University [ERAU], 2016). Surface density altitude corrections are shaded in thousands of feet.

\section{Interdisciplinary Weather Support}

As an example, Figure 4 shows a model forecast surface density altitude correction map produced on the ERAU-DB flight weather website (http://fltwx.db.erau.edu/aviationfcst.php) for 2100 UTC 26 July 2016. The ARC weather support team is not required to use ERAU-DB proprietary products, but the density altitude correction maps are useful weather support products that happen to be produced in-house. Although the chart shown was not from the 2016 ARC, the meteorological conditions over the southwest U.S. and Texas were quite similar to the first two legs of the 2016 ARC. That is, surface density altitude corrections over much of Arizona, New Mexico, and western Texas were $>3000 \mathrm{ft}$. The practical implications of such density altitude corrections are that for the C-172 aircraft (see Figure 2), the service ceilings become e.g. Flight 
Level (FL)110 (11000 ft.) during the heat of the day. This limits the altitudes and times at which these aircraft can fly, the tailwinds they can take advantage of, or all of the above. During the 2016 ARC, the majority of the first two race legs (see Figure 1) had to be completed at cooler times of day, either early in the morning or in the early evening.

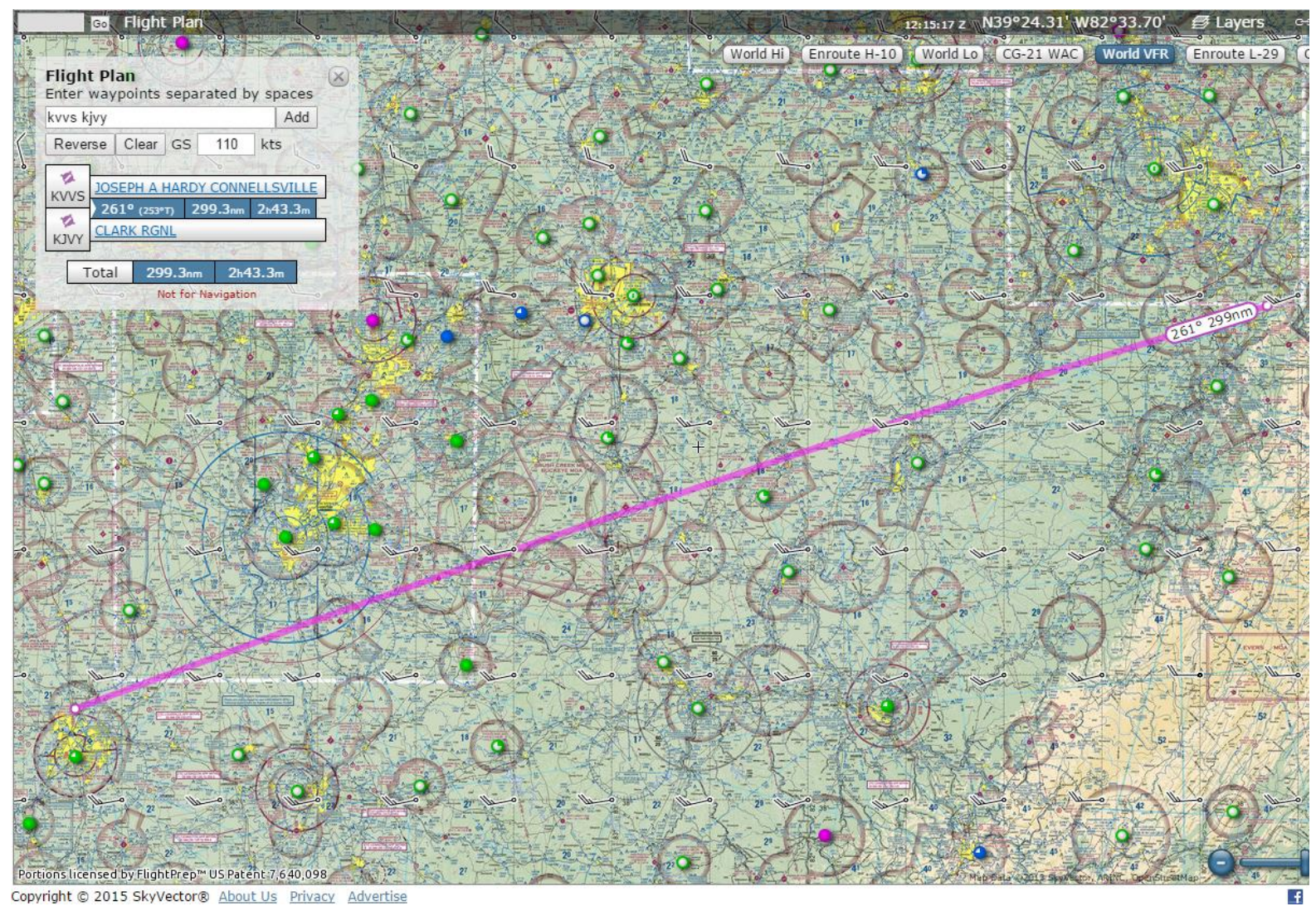

Figure 5. SkyVector aeronautical chart 9-hour forecast of Flight Level (FL)030 (3000 ft.) winds, valid at 2100 UTC 22 June 2015 (SkyVector, 2015). Winds (barbs) are plotted in knots.

Other weather observation and forecasting tools integrated into the pre-race lectures included basic knowledge of radar coverage areas and identification of locations along each race leg that had regular hourly surface observations and Terminal Aerodrome Forecasts (TAFs). In addition, one of the primary issues with students from predominantly aviation backgrounds is their frequent use of online wind forecast websites such as SkyVector (SkyVector, 2015) and ForeFlight (ForeFlight, 2016). During the 2014 ARC, it was apparent that aeronautical science 
students would rely on SkyVector as forecast truth rather than as one possible outcome. In reality, it is important for students to not solely rely on "black-box" forecasting tools such as SkyVector and ForeFlight, which are only as accurate as the numerical weather prediction (NWP) model that they are based on, most commonly the National Oceanic and Atmospheric Administration (NOAA) National Centers for Environmental Prediction (NCEP) North American Mesoscale (NAM). By definition, NWP models contain error, and that error typically grows exponentially with greater lead time. Thus, it is very important that the weather support team uses multiple NWP models and human forecasts throughout the ARC. It is also crucial that real-time observations (e.g., radar, satellite, surface station observations, radiosonde data) are used to help confirm NWP model forecasts.

Figure 5 shows a SkyVector chart of the 9-hour forecast FL030 winds, valid at 2100 UTC 22 June 2015, from Connellsville, Pennsylvania (KVVS, east) to Jeffersonville, Indiana (KJVY, west). It was clear during the morning of 22 June 2015 that the ARC race teams would be facing headwinds during this race leg, which they flew around 2100 UTC. The challenges for the weather support team were to: (a) find the flight level at which the headwinds could be best mitigated, and (b) ensure by departure time from KVVS that the forecasts matched with current observations.

\section{Integrating Aviation into Meteorology}

Many ERAU-DB meteorology majors, although familiar with basic aviation concepts (e.g., altimetry, density altitude), come into the ARC course lacking specific aviation knowledge needed to provide ARC weather support. For example:

- Which airfield facilities are available at each ARC leg terminus? 
Journal of Aviation/A erospace Education \& Research, Vol. 26, No. 2 [2017], Art. 4

- Does each airfield have services and ramp space to handle an onslaught of up to 50 single engine aircraft wanting a quick turn around? If not, it is important to ensure that the supported aircraft do not get caught up in the pack by properly timing their arrival into that location.

- What are the weights, fuel burn rates, capacities, and service ceilings of each aircraft?

- What is a MOA or restricted area? In both 2014 and 2015, the ARC race courses ran near the Washington DC restricted area. As a result:

- All students are required to take the online FAA safety course $A L C-55$ : Washington DC Special Flight Rules Area (SFRA) (FAA, 2016b).

The answers to all of these questions are needed to plan the optimum flight level and routing for each leg of the race. From here, the operational weather support phase of the ARC course is discussed.

\section{Example Forecast Scenario: The 2015 ARC}

Figure 5 shows a SkyVector (SkyVector, 2015) 9-hour forecast wind chart valid at 2100 UTC 22 June, depicting general headwinds during the KVVS-KJVY leg of the 2015 ARC. Some of the other forecast and observational meteorological tools used to provide weather support during that particular leg are now presented.

Figure 6 shows an atmospheric radiosonde (weather balloon) sounding from Wilmington, Ohio (KILN) at 1200 UTC 22 June. KILN is located along the KVVS-KJVY flight path, and this sounding is one of the observational tools that the weather support team examines during the morning of a race day. It was clear at 1200 UTC that west-to-east headwinds had already set up along the flight path from FL030 ( 900 millibars) to the aircraft service ceiling (FL140, 550 millibars), and forecast models had them generally increasing throughout the day (see Figure 5). 


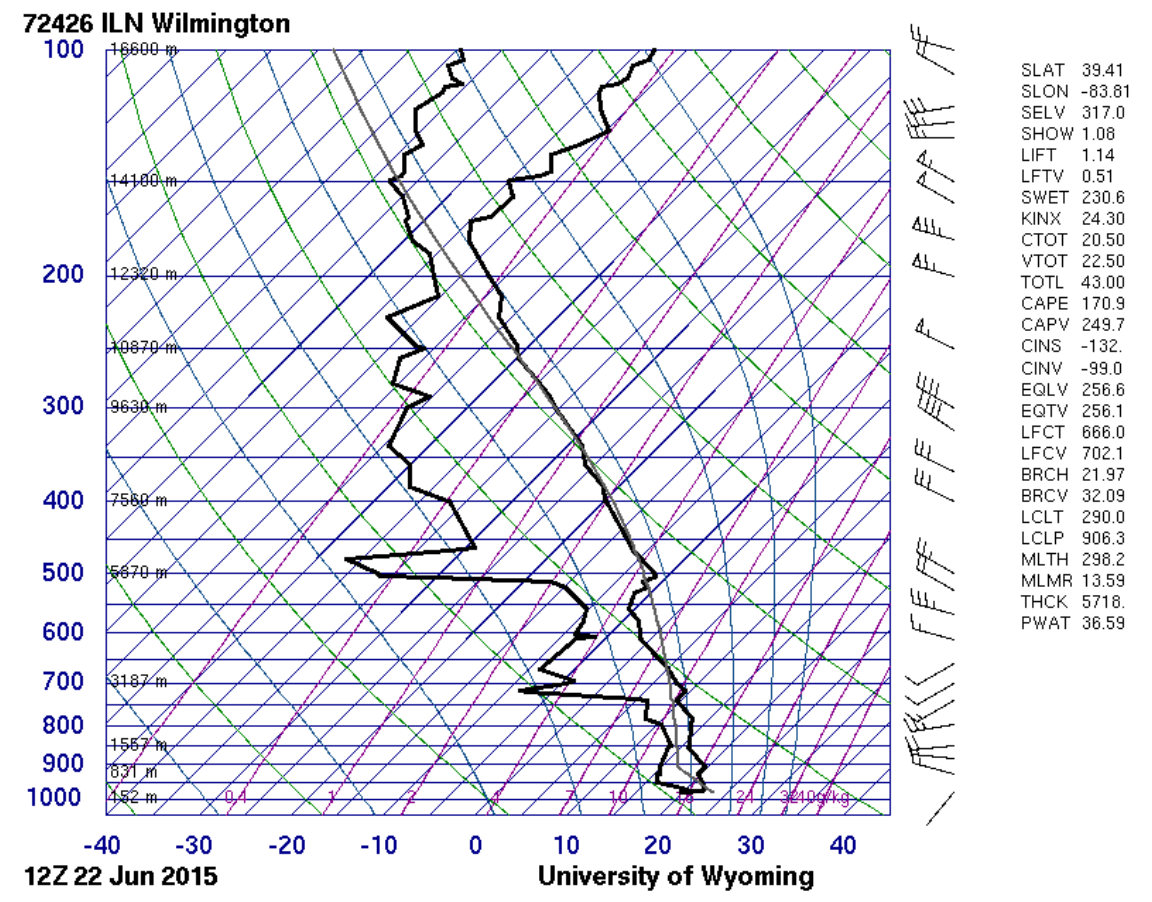

Figure 6. Atmospheric radiosonde sounding for KILN (Wilmington, Ohio) at 1200 UTC 22 June 2015 (University of Wyoming Department of Atmospheric Science, 2015). Temperature (right black line) and dewpoint (left black line) are in ${ }^{\circ} \mathrm{C}$, pressure is in millibars and height is in meters on the left-hand vertical axis, and winds (barbs) are plotted in knots on the right-hand vertical axis.

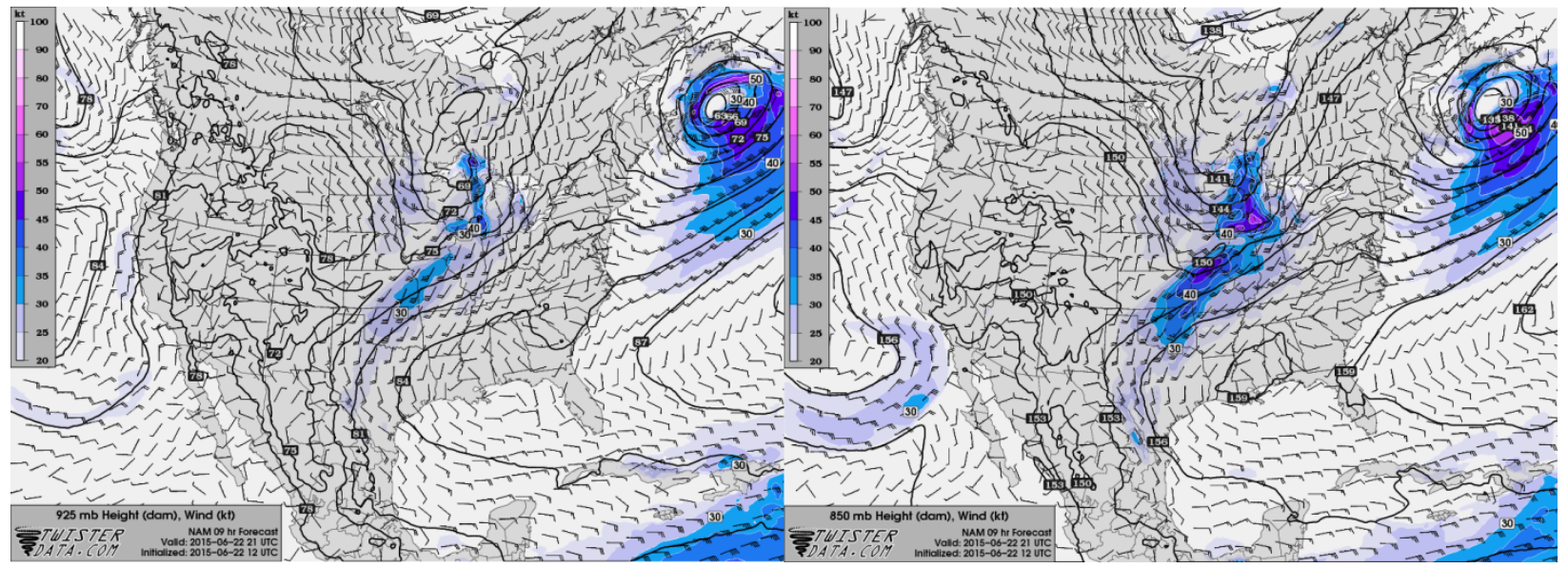

Figure 7. National Oceanic and Atmospheric Administration (NOAA) National Centers for Environmental Prediction (NCEP) North American Mesoscale (NAM) model 925 millibar (left) and 850 millibar (right) 9-hour wind forecasts from 1200 UTC 22 June 2015 (Twister Data, 2015), valid at 2100 UTC 22 June 2015. Winds are plotted in knots (barbs) and geopotential height (solid black) is in meters. 

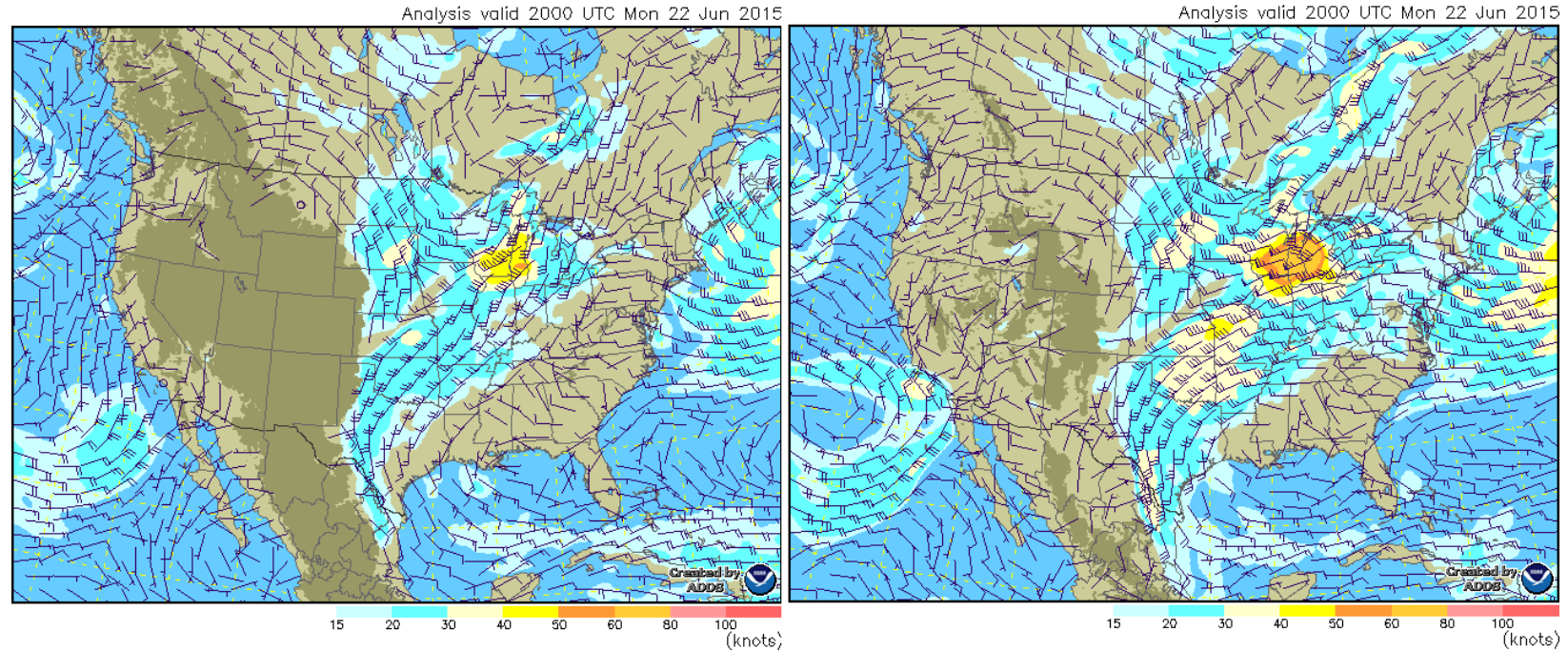

Figure 8. Aviation Weather Center (AWC) Aviation Digital Display Service (ADDS) FL030 (900 mb, left) and FL060 (800 mb, right) wind charts for 2100 UTC 22 June 2015 (Aviation Weather Center [AWC], 2015a). Winds (barbs) are plotted in knots and wind speed in knots is shaded. The altitude and pressure levels are considered equivalent by AWC ADDS.

One of the decisions that had to be made for the KVVS-KJVY leg was which flight level was optimal to minimize the impact of headwinds. In addition to SkyVector (see Figure 5), the weather support team examined the NAM forecast model at 925, 850, and 700 millibars, nine hours prior to the KVVS-KJVY leg. As shown in Figure 7 (Twister Data, 2015), the headwinds were clearly forecast to be weaker at lower altitudes (925 millibars) than at slightly higher altitudes (850 millibars). As a result, the weather support team advised the ARC racers to fly as low as possible into KJVY.

As the ARC teams arrived in KVVS, the weather support team started to use real-time observations and short-term forecast models to try to confirm the longer-range forecast model predictions. One of these sources is the Aviation Weather Center (AWC) Aviation Digital Display Service (ADDS) wind charts (AWC, 2015a), produced every hour. Examples of the FL030 and FL060 maps from 2000 UTC 22 June 2015 are shown in Figure 8. These charts 
confirmed the earlier NAM model predictions of weaker headwinds at lower altitudes over Ohio and Indiana, which increased forecast confidence.

Other observational tools used by the weather support team are shown in Figures 9 and 10. Figure 9 shows the KILN radar Vertical Azimuth Display (VAD) wind profiler (College of DuPage, 2015); the VAD tool measures the real-time winds directly above the radar up to approximately FL100. For ARC weather support, the VAD is used as an assessment of the forecast and also to adjust to real-time conditions "on the fly." For the KVVS-KJVY leg, the VAD confirmed forecasts of slightly weaker headwinds at lower altitudes. Figure 10 shows the AWC ADDS Flight Path Cross-Section Tool (AWC, 2015b), which also provides real-time wind and relative humidity (cloud) information. The similarities in the wind profiles in Figures 9 and 10 are obvious; having multiple real-time observational tools confirm the forecast gave the weather support team increased confidence, and resulted in the highest possible ground speed for the ARC race teams.

\section{Adaptations for the 2016 ARC}

One of the necessary tasks of the weather support team in a four-day air race is to think beyond the forecast for the next few hours. It was evident during the 2014 and 2015 ARC courses that this type of thinking does not always come naturally, particularly to aviationoriented students. While students are taught and encouraged to examine common weather forecast models such as the NAM that go out 2-4 days in the future, students better understand the value of these longer-range forecasts when they are able to later verify them with shorterrange forecast models and real-time observations.

One of the primary short-term forecast models used during the course was the NOAA NCEP High-Resolution Rapid Refresh (HRRR), which updates each hour with forecasts out to 
Journal of Aviation/A erospace Education \& Research, Vol. 26, No. 2 [2017], Art. 4

18 hours. The HRRR is not, to the authors' knowledge, currently used to produce "black box" flight wind forecasts (e.g., SkyVector), so introducing the students to it and how to use it is an important task during the pre-race lectures.

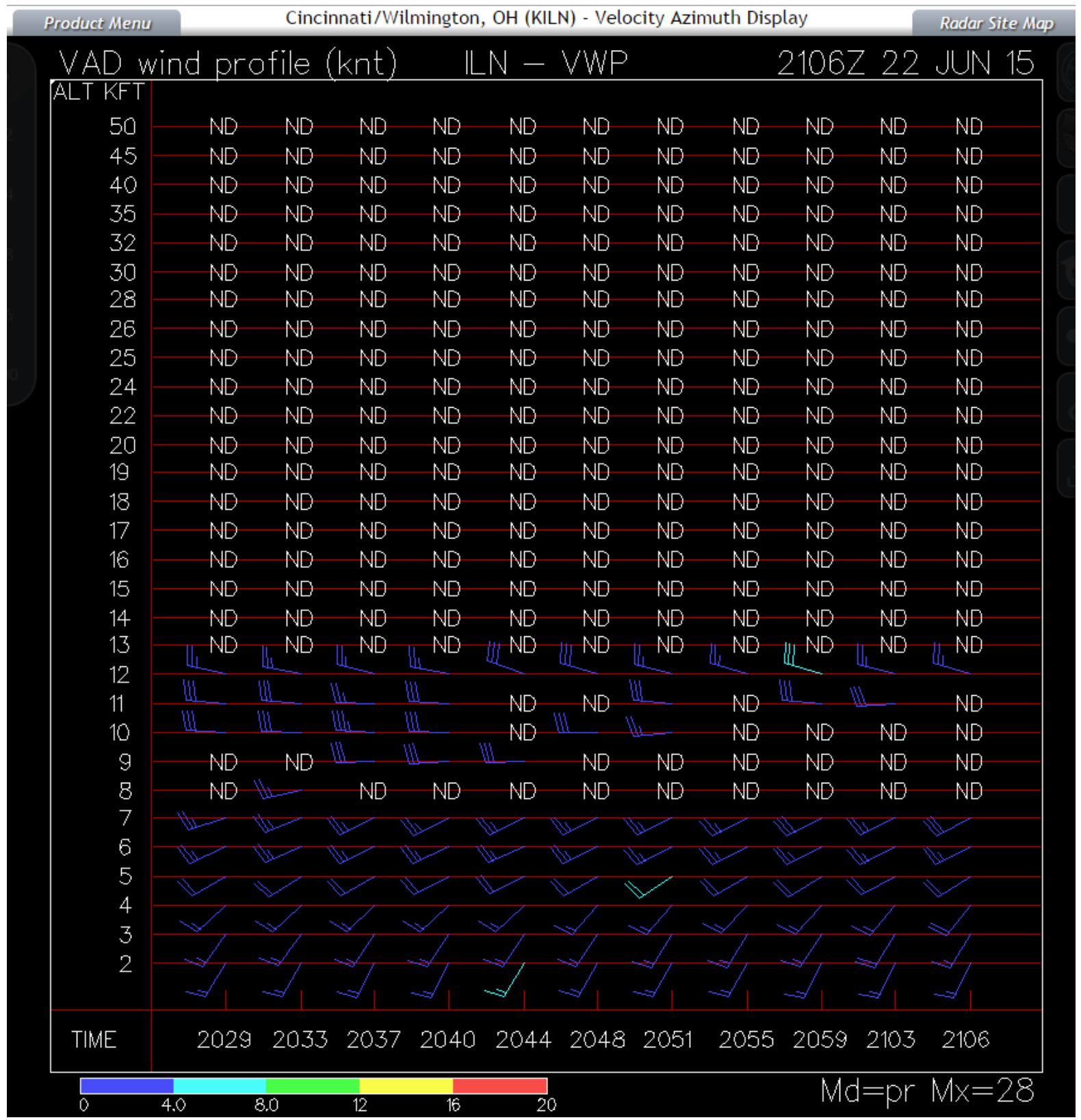

Figure 9. NEXRAD Radar Vertical Azimuth Display (VAD) wind profiler data from KILN (Wilmington, Ohio) at 2106 UTC 22 June 2015 (College of DuPage, 2015). Winds (barbs) are plotted in knots, with time moving forward from left to right. 


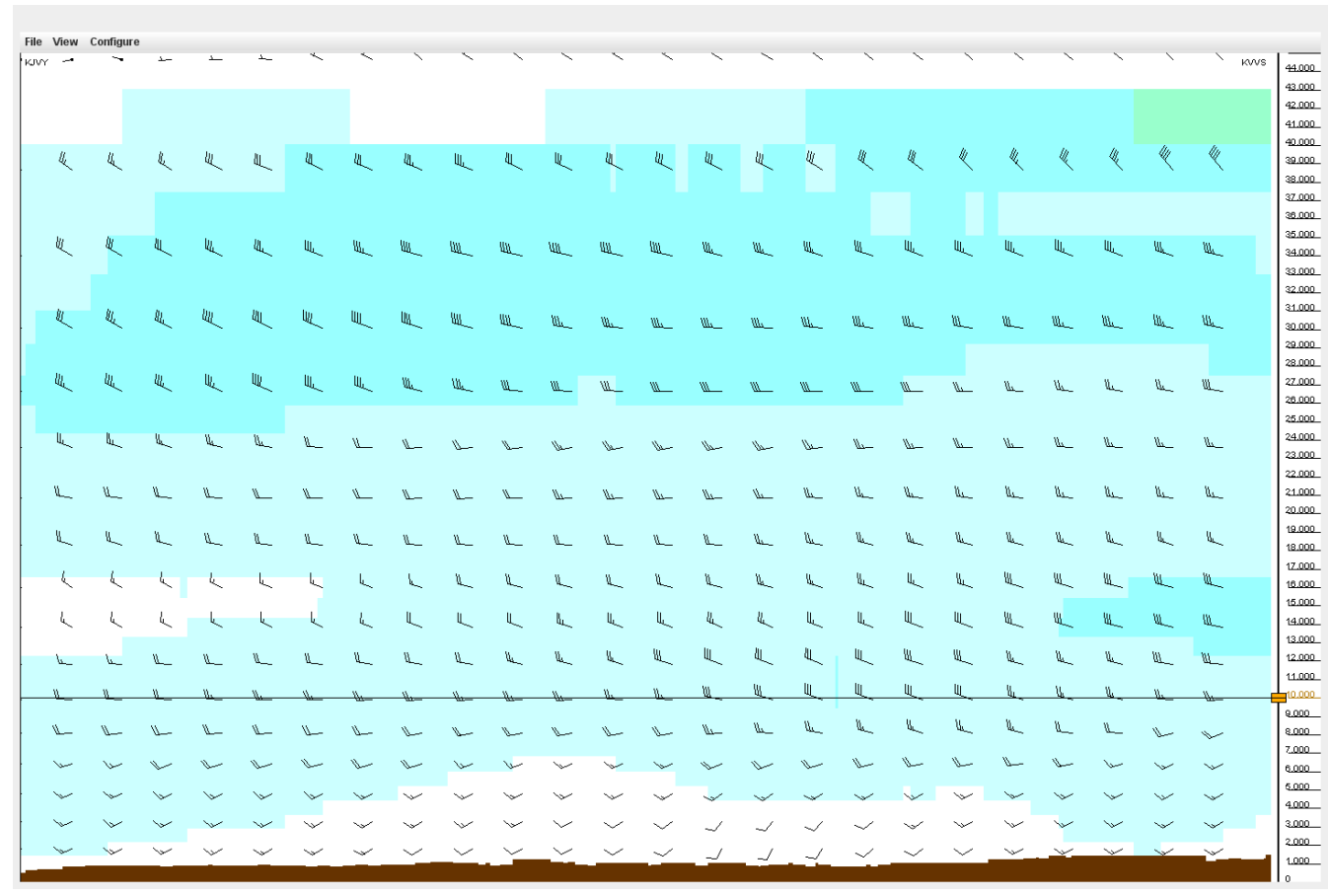

Figure 10. AWC ADDS Flight Path Cross-Section Tool from (right to left) Connellsville, Pennsylvania (KVVS) to Jeffersonville, Indiana (KJVY) at 2100 UTC 22 June 2015 (AWC, 2015b). Winds (barbs) are plotted in knots, with altitude above mean-sea level on the right-hand side.

The plots in Figure 11 were created using the General Meteorological Package (GEMPAK) version 7.0.0, updated from the original devised by Koch, desJardins, and Kocin (1983). Figure 11 shows 6-hour HRRR forecasts of wind speed and direction, valid at 2100 UTC 23 June 2016 (National Oceanic and Atmospheric Administration National Centers for Environmental Prediction [NOAA NCEP], 2016). The race leg was from Warrensburg, Missouri (KRCM) to Champaign, Illinois (KCMI, see Figure 1). The previous day, the weather support team forecast 20-30 knot tailwinds on this leg, but the exact flight level where the tailwinds would be most advantageous was uncertain (not shown). Figure 11 shows that tailwinds were forecast by the HRRR to be stronger at higher altitudes; tailwinds at FL100 were forecast to be 20-45 knots between KLSX and KCMI, while only 15-25 knots at FL050. As such, the weather support team advised the race teams to fly near or at FL100, especially northeast of KLSX. 
Journal of Aviation/A aerospace Education \& Research, Vol. 26, No. 2 [2017], Art. 4

700 millibars (FL100)
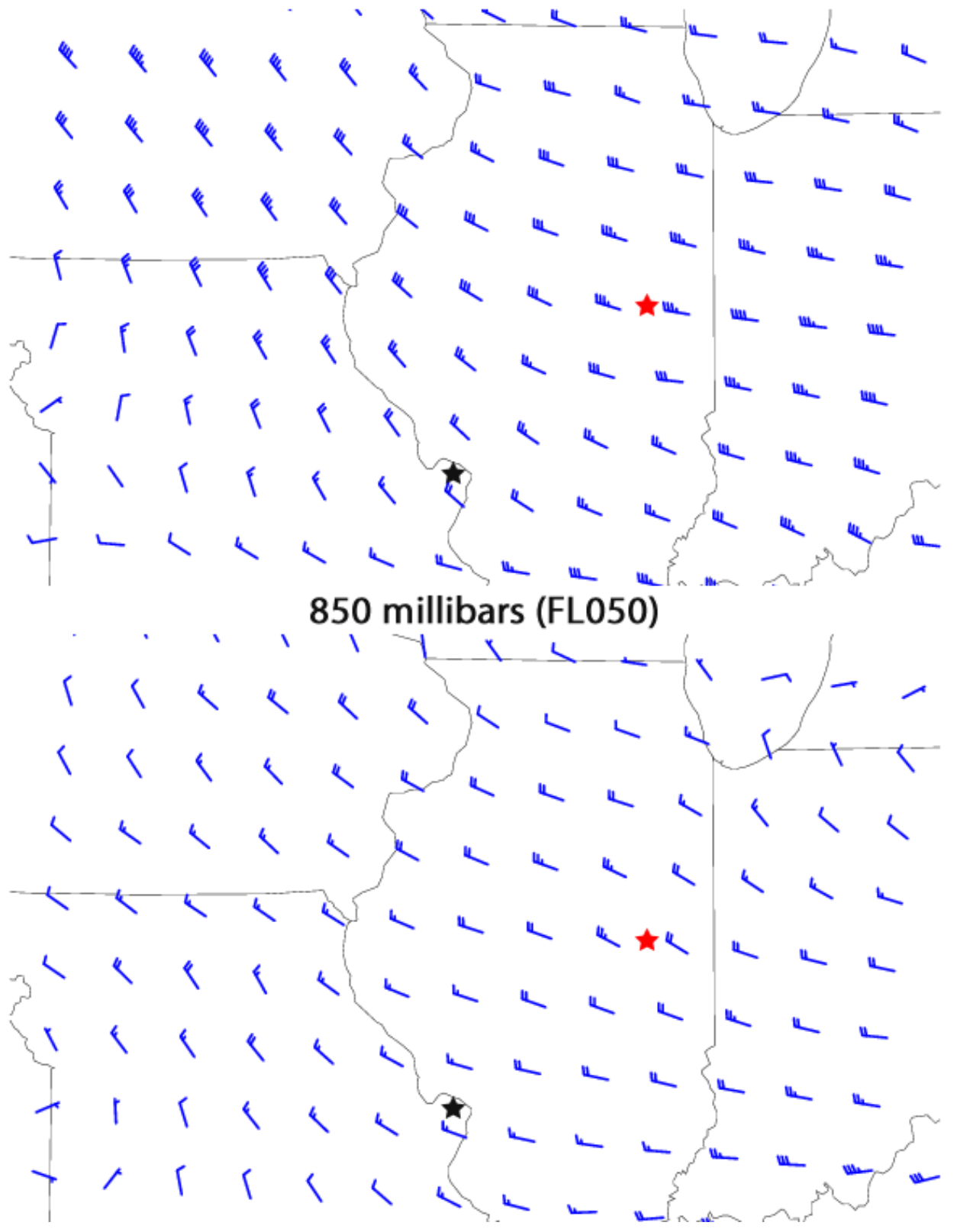

Figure 11. NOAA NCEP High-Resolution Rapid Refresh (HRRR) model (NOAA NCEP, 2016) six-hour wind forecasts from 1500 UTC 23 June 2016, valid at 2100 UTC 23 June 2016 for (top) 700 millibars (FL100) and (bottom) 850 millibars (FL050). Winds (barbs) are plotted in blue in knots. The black and red stars depict the approximate locations of the KLSX (St. Louis, Missouri) NEXRAD radar (see Figure 12) and the Champaign/Urbana, Illinois airport (KCMI, see Figure 1), respectively.

https://commons.erau.edu/jaaer/vol26/iss2/4

DOI: https://doi.org/10.15394/jaaer.2017.1715

130 


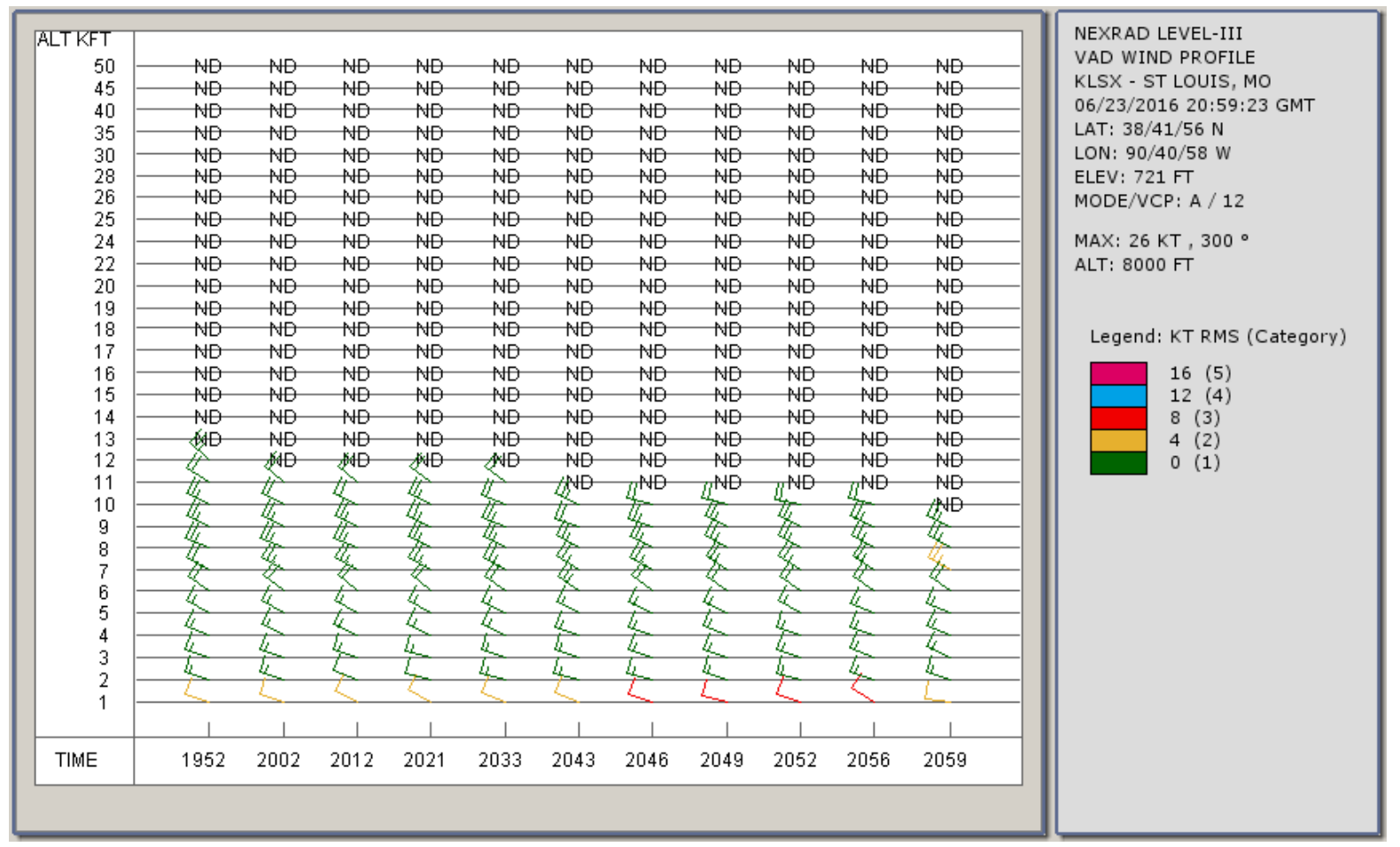

Figure 12. NEXRAD Radar VAD wind profiler data from KLSX (St. Louis, Missouri) at 2059 UTC 23 June 2016 (NOAA National Centers for Environmental Information [NOAA NCEI], 2016). Winds (barbs) are plotted in knots, with time moving forward from left to right.

While the HRRR model provided valuable short-term forecast skill, it is still important to verify all forecasts with real-time observations. As during the 2015 ARC, NEXRAD radar VAD wind profiler data from various radars along the race paths was used to evaluate the weather support team's forecasts. Figure 12 shows an example of such from the KLSX radar at 2059 UTC 23 June 2016 (NOAA NCEI, 2016), as the race teams were flying the KRCM-KCMI race leg. The VAD observed 20-25 knot tailwinds above FL080, consistent with the HRRR forecasts seen in Figure 11. These observations gave the weather support team confidence that their forecast was accurate and that the race teams were at the most appropriate altitude (FL100) to experience the best possible tailwinds. 


\section{Conclusions}

\section{Summary}

This paper details the ERAU-DB interdisciplinary service-learning approach to weather support for the ARC, through development of a three-credit summer course. By staffing the ARC weather support team with a combination of aeronautical science students studying to be professional pilots and/or FAA dispatchers, and meteorology students, useful and cohesive weather support has been given to the ARC racers, contributing to strong ERAU-DB ARC finishes since 2013 (see Table 1). Prior to organized weather support being offered in 2013, the ERAU-DB race teams finished on average in $16^{\text {th }}$ place overall in the ARC from 2007-2012. Since 2013, the ERAU-DB race teams have finished on average in $3^{\text {rd }}$ place overall, demonstrating the value of cohesive and collaborative weather support.

Throughout this experience, students from various educational backgrounds learned to work more cohesively in a team environment. Moreover, they were exposed to weather and aviation support tools and concepts they may not have been previously aware of. As examples, meteorology students had to learn about MOAs, service ceilings, and fuel burns, while pilots and dispatchers were exposed to an entire new set of real-time observational (e.g., VAD wind profilers, see Figures 5 and 12) and forecast model tools (e.g., HRRR, see Figure 11).

\section{Lessons Learned and Future Applications}

Eyler (2002) stated that one of the primary assessments for service-learning is constant student reflection, alone, with classmates, and later, with community partners (i.e., the ARC racers). To illustrate this point, below are five different students' reflections in journal entries collected during the 2014-2015 ARC courses: 
- "Students are expected to think on their feet, analyze real-time developments, and make decision-worthy predictions about weather. I feel that this class is an invaluable step in moving the weather outside the classroom and into a meaningful situation."

- "I have learned more from this one weather class than I have taking four other weather courses. This class allows for students to get real world planning and information. As a pilot this is very useful having this kind of training, (as) I am able to plan out a flight a week in advance because of the skills I have learned in this class. Having a meteorology major in my group helped me learn how to read moisture graphs, wind charts, and temperature charts better, and use all of them to plan a route in the future."

- "I would have never thought that flying VFR would be so complicated. (Issues range) from morning fog, convective cells, mountains, large towers, restricted areas, and overall IFR conditions."

- "One of the most important things I learned in this class is to trust and communicate well with your team members."

The student reflections indicate that the ARC course was successful in integrating students from different educational backgrounds into a productive and resourceful weather support team. In addition, the class allowed the students to feel a sense of purpose to the ERAUDB community, and put them in real-world situations where users were depending on their job performance, advice, and decision-making. Finally, in future years, a skill assessment of the various weather support tools used during the ARC will be performed. Specifically, a quantitative comparison of model-based forecast tools such as SkyVector (SkyVector, 2015) and ForeFlight (ForeFlight, 2016), observations (e.g., wind speeds derived from radar), and actual results (i.e., aircraft ground speed) is warranted. 


\section{References}

Air Race Classic (ARC). (2016a). Air Race Classic History. Retrieved from http://airraceclassic.org/historyt.asp

Air Race Classic (ARC). (2016b). [Graph Illustration the 2015 and 2016 Air Race Classic Route Maps]. Air Race Classic. Retrieved from http://airraceclassic.org/

Aviation Weather Center (AWC). (2015a). [Graph Illustration the FL030 and FL060 Winds Valid at 2000 UTC 22 June 2015]. Aviation Digital Data Service (ADDS). Retrieved from http://www.aviationweather.gov/adds/

Aviation Weather Center (AWC). (2015b). [Graph Illustration the Flight Path Cross-Section Tool Valid at 2100 UTC 22 June 2015]. ADDS Flight Path Tool. Retrieved from https://www.aviationweather.gov/flightpath

Boyer, E. L. (1994). Creating the New American College. Chronicle of Higher Education, $48,9$. College of DuPage. (2015). [Graph Illustration the Vertical Azimuth Display (VAD) Wind Profile from KILN at 2106 UTC 22 June 2015]. Next Generation Weather Lab (Nexlab) Nexrad Single Site Radar. Retrieved from http://weather.cod.edu/satrad/

Embry-Riddle Aeronautical University (ERAU). (2016). [Graph Illustration the Forecast Surface Density Altitude Correction for 2100 UTC Tuesday 26 July 2016]. Embry-Riddle Flight Weather Aviation Weather Forecast Images. Retrieved from http://fltwx.db.erau.edu/get_loop.php?\&cnt=27\&dir=model_erau/NAM/FDALT/US/

Eyler, J. (2002). Reflection: Linking service and learning - linking students and communities. Journal of Social Issues, 58(3), 517-534. https://doi.org/10.1111/1540-4560.00274 
Eyler, J., \& Giles Jr, D. E. (1999). Where's the Learning in Service-Learning? Jossey-Bass Higher and Adult Education Series. Jossey-Bass, Inc., 350 Sansome St., San Francisco, CA 94104.

Federal Aviation Administration (FAA). (2016a). VFR Raster Charts [Data File]. Retrieved from https://www.faa.gov/air_traffic/flight_info/aeronav/digital_products/vfr/

Federal Aviation Administration (FAA). (2016b). ALC-55: Washington D.C. Special Flight Rules Area (SFRA) [Data File]. Retrieved from https://www.faasafety.gov/gslac/ALC/course_content.aspx?cID=55\&preview=true ForeFlight. (2016). ForeFlight Web [Data File]. Retrieved from https://www.foreflight.com/products/foreflight-web/

Furco, A., Jones-White, D., Huesman, R., Jr., \& Gorny, L. S. (2016). Modeling the Influence of Service-Learning on Academic and Sociocultural Gains: Findings from a Multiinstitutional Study. In Civic Engagement and Community Service at Research Universities (pp. 143-163). Palgrave Macmillan UK. https://doi.org/10.1057/978-1-137$55312-6 \_8$

Koch, S., desJardins, M., \& Kocin, P. (1983). An interactive Barnes objective map analysis scheme for use with satellite and conventional data. Journal of Applied Meteorology, 22, 1487-1503. https://doi.org/10.1175/1520-0450(1983)022<1487:AIBOMA>2.0.CO;2

Kricsfalusy, V., George, C., \& Reed, M. G. (2016). Integrating problem- and project-based learning opportunities: Assessing outcomes of a field course in environment and sustainability. Environmental Education Research, 1-18. https://doi.org/10.1080/13504622.2016.1269874 
National Oceanic and Atmospheric Administration (NOAA) National Centers for Environmental Information (NCEI). (2016). [Graph Illustration the Vertical Azimuth Display (VAD) Wind Profile from KLSX at 2059 UTC 23 June 2016]. NCEI Radar Data NEXRAD Inventory. Retrieved from http://www.ncdc.noaa.gov/nexradinv/

National Oceanic and Atmospheric Administration (NOAA) National Centers for Environmental Prediction (NCEP). (2016). High-Resolution Rapid Refresh (HRRR) Model [Data File]. Retrieved from http://www.nco.ncep.noaa.gov/pmb/products/hrrr/

SkyVector. (2015). [Graph Illustration the 9-hour Wind Forecast Valid at 2100 UTC 22 June 2015]. Sky Vector Aeronautical Charts. Retrieved from http://skyvector.com/

Twister Data. (2015). [Graph Illustration the North American Mesoscale (NAM) Model 9-hour Wind Forecast Valid at 2100 UTC 22 June 2015] NAM Model. Retrieved from http://www.twisterdata.com/

University of Wyoming. (2015). [Graph Illustration the KILN Atmospheric Sounding from 1200 UTC 22 June 2015]. Department of Atmospheric Science Archived Soundings. Retrieved from http://weather.uwyo.edu/upperair/sounding.html 